Short Communication

\title{
A THEORETICAL STUDY OF THE INHIBITION OF WILD-TYPE AND DRUG-RESISTANT HIV-1 REVERSE TRANSCRIPTASE BY SOME THIAZOLIDENEBENZENESULFONAMIDE DERIVATIVES
}

\author{
FRANCISCO SOTO-MORALES ${ }^{I^{*}}$ AND JUAN S. GÓMEZ-JERIA².
}

\author{
${ }^{1}$ Américo Vespucio 642, Santiago, Chile. \\ ${ }^{2}$ Universidad de Chile, Facultad de Ciencias, Departamento de Química. Casilla 653 Santiago 21, Chile, and Programa de Doctorado en Fisicoquímica \\ Molecular, Universidad Andrés Bello. República 275, Santiago, Chile. \\ (Received $24^{\text {th }}$ January $2007-$ Accepted $2^{\text {nd }}$ May 2007)
}

\begin{abstract}
We present the results of a quantum chemical study of the relationship between the electronic-conformational structure of a group of thiazolidenebenzenesulfo namide derivatives (TBS) and their Immunodeficiency Type 1 Virus (HIV-1) Reverse Transcriptase (RT, the wild one and two mutated types) inhibitory capacity. Our results show that the variation of the inhibitory capacity of TBS against the three types of HIV-1 RTs is regulated by different mechanisms. Also, as expected in a highly specific interaction, molecular orbitals other than the frontier molecular orbitals seem to regulate the inhibition of RT by TBS. The increase of the inhibitory capacity with increasing size of some substituents is not attributable to their interaction with a hydrophobic site but to their effect on the distribution of the rotational velocities. Specific $\pi-\pi$ stacking interactions are the main components of the TBS-RT coupling. For each type of RT, the results provide a list of sites in the common skeleton that can be modulated through substitution to improve the inhibitory capacity.
\end{abstract}

Keywords: ZINDO/1, HIV-1 Reverse Transcriptase, Thiazolidenebenzenesulfonamide, KPG method, structure-activity relationships.

\section{INTRODUCTION}

The acquired immunodeficiency syndrome (AIDS) is the latest pandemic affecting mankind. AIDS is produced by the action of the human Immunodeficiency Type 1 virus. No cure is known yet, but infected humans may remain in good general health and prolong their lives employing various pharmacological therapies ${ }^{1-4}$. HIV-1 exerts its action through at least four mechanisms $^{5}$. One of these involves the virus reverse transcriptase ${ }^{6}$. The HIV-1 RT catalyzes the conversion of the viral genomic RNA into a double-stranded proviral DNA after entering the cell ${ }^{7}$. The final result of this process is the multiplication of the HIV-1 virus inside the host cell.

For this reason HIV-1 RT is an attractive target for developing anti-HIV drugs.

Several drug families that inhibit this enzyme have been approved to treat AIDS. One of these is the group of non-nucleoside reverse transcriptase inhibitors (NNRTIs). These compounds are highly active against HIV-1, but inactive against HIV-2 or any other retrovirus. They interact non-competitively with a hydrophobic pocket, called non-nucleoside inhibitor-binding pocket, which is located about $10 \AA$ away from the catalytic site ${ }^{8}$ and upon occupation by an NNRTI forces the HIV-1 RT subunit into an inactive conformation? Although the therapeutic use of NNRTIs is complicated by the rapid development of viral resistance due to single amino acid mutations ${ }^{10,11}$ in the NNRTI-binding pocket that directly affect drug binding ${ }^{12,13}$, they have proven to be useful in combination with other RT and protease inhibitors ${ }^{14}$.

Recently the reverse transcriptase inhibitory capacity of a series of thiazo lidenebenzenesulfonamides, a new class of NNRTIs, was reported (Fig. 1) 15,16. $^{15}$. The biological systems employed to test the inhibitory capacity of these drugs were the wild-type (WT) HIV-1 RT, and two of its drug-resistant mutations. In the first one, Lys-103 was mutated to Asp (K103N-RT), and in the second, Tyr-181 was replaced by Cys (Y181C-RT). Due to the pressing need to develop new anti-HIV drugs, we present here the results of a theoretical study of the relationship between the electronic-conformational structure of a group of TBS derivatives and their RT-inhibitory capacity.<smiles>[R3]c1s/c(=N\S(=O)(=O)c2c([R])c([R])c([2H])c([R])c2[R6])n([R])c1[R]</smiles>

$1 \mathbf{R}_{1}=\mathrm{Me}, \mathbf{R}_{2}=\mathrm{H}, \mathbf{R}_{3}=\mathrm{t}-\mathrm{Bu}, \mathbf{R}_{4}=\mathrm{NO}_{2}, \mathbf{R}_{5}=\mathrm{H}, \mathbf{R}_{6}=\mathrm{H}, \mathbf{R}_{7}=\mathrm{H}$

$2 \mathbf{R}_{1}=\mathrm{Me}, \mathbf{R}_{2}=\mathrm{Me}, \mathbf{R}_{3}=\mathrm{t}-\mathrm{Bu}, \mathbf{R}_{4}=\mathrm{NO}_{2}, \mathbf{R}_{5}=\mathbf{H}, \mathbf{R}_{6}=\mathbf{H}, \mathbf{R}_{7}=\mathbf{H}$

$3 \mathbf{R}_{1}=$ Me, $\mathbf{R}_{2}=\mathrm{Et}, \mathbf{R}_{3}=\mathrm{t}-\mathrm{Bu}, \mathbf{R}_{4}=\mathrm{NO}_{2}, \mathbf{R}_{5}=\mathbf{H}, \mathbf{R}_{6}=\mathbf{H}, \mathbf{R}_{7}=\mathbf{H}$

$4 \mathbf{R}_{1}=\mathrm{Me}, \mathbf{R}_{2}=\mathrm{Me}, \mathrm{R}_{3}=\mathrm{Me}, \mathbf{R}_{4}=\mathrm{NO}_{2}, \mathbf{R}_{5}=\mathrm{H}, \mathbf{R}_{6}=\mathrm{H}, \mathbf{R}_{7}=\mathrm{H}$

$5 \quad R_{1}=\mathrm{Me}, \mathbf{R}_{2}=\mathrm{Me}, \mathbf{R}_{3}=\mathrm{Et}, \mathbf{R}_{4}=\mathrm{NO}_{2}, \mathbf{R}_{5}=\mathrm{H}, \mathbf{R}_{6}=\mathrm{H}, \mathbf{R}_{7}=\mathrm{H}$

$6 \mathbf{R}_{1}=\mathrm{Me}, \mathbf{R}_{2}=\mathrm{Me}, \mathbf{R}_{3}=\mathrm{i}-\mathrm{Pr}, \mathbf{R}_{4}=\mathrm{NO}_{2}, \mathbf{R}_{5}=\mathrm{H}, \mathbf{R}_{6}=\mathrm{H}, \mathbf{R}_{7}=\mathrm{H}$

$7 \mathbf{R}_{1}=\mathbf{H}, \mathbf{R}_{2}=\mathrm{Me}, \mathbf{R}_{3}=\mathrm{i}-\mathrm{Pr}, \mathbf{R}_{4}=\mathrm{NO}_{2}, \mathbf{R}_{5}=\mathbf{H}, \mathbf{R}_{6}=\mathbf{H}, \mathbf{R}_{7}=\mathbf{H}$

$8 \quad \mathbf{R}_{1}=\mathbf{C F}_{3}, \mathbf{R}_{2}=\mathrm{Me}, \mathbf{R}_{3}=\mathrm{i}-\mathrm{Pr}, \mathbf{R}_{4}=\mathrm{NO}_{2}, \mathbf{R}_{5}=\mathbf{H}, \mathbf{R}_{6}=\mathbf{H}, \mathbf{R}_{7}=\mathbf{H}$

$9 \mathbf{R}_{1}=\mathrm{Cl}, \mathbf{R}_{2}=\mathrm{Me}, \mathbf{R}_{3}=\mathrm{i}-\mathrm{Pr}, \mathbf{R}_{4}=\mathrm{NO}_{2}, \mathbf{R}_{5}=\mathbf{H}, \mathbf{R}_{6}=\mathbf{H}, \mathbf{R}_{7}=\mathbf{H}$

$10 \mathbf{R}_{1}=\mathrm{Me}, \mathbf{R}_{2}=\mathrm{Me}, \mathbf{R}_{3}=\mathrm{CH}=\mathrm{CH}_{2}, \mathbf{R}_{4}=\mathrm{NO}_{2}, \mathbf{R}_{5}=\mathrm{H}, \mathbf{R}_{\mathbf{6}}=\mathrm{H}, \mathbf{R}_{7}=\mathrm{H}$

$11 R_{1}=\mathrm{CONH}_{2}, \mathrm{R}_{2}=\mathrm{Me}, \mathrm{R}_{3}=\mathrm{i}-\mathrm{Pr}, \mathrm{R}_{4}=\mathrm{NO}_{2}, \mathrm{R}_{5}=\mathrm{H}, \mathbf{R}_{6}=\mathrm{H}, \mathrm{R}_{7}=\mathrm{H}$

$12 \mathbf{R}_{1}=\mathrm{CN}, \mathbf{R}_{2}=\mathrm{Me}, \mathbf{R}_{3}=\mathrm{i}-\mathrm{Pr}, \mathbf{R}_{4}=\mathrm{NO}_{2}, \mathbf{R}_{5}=\mathbf{H}, \mathbf{R}_{\mathbf{6}}=\mathbf{H}, \mathbf{R}_{7}=\mathrm{H}$

$13 R_{1}=M e, R_{2}=M e, R_{3}=t-B u, R_{4}=\mathrm{Cl}, R_{5}=H, R_{6}=H, R_{7}=H$

$14 R_{1}=\mathrm{Me}, R_{2}=\mathrm{Me}, R_{3}=\mathrm{t}-\mathrm{Bu}, \mathbf{R}_{4}=\mathrm{H}, \mathbf{R}_{5}=\mathrm{OMe}, \mathrm{R}_{6}=\mathrm{H}, \mathrm{R}_{7}=\mathrm{H}$

$15 R_{1}=M e, R_{2}=M e, R_{3}=t-B u, R_{4}=O M e, R_{5}=H, R_{6}=H, R_{7}=H$

$16 R_{1}=M e, R_{2}=M e, R_{3}=t-B u, R_{4}=H, R_{5}=H, R_{6}=H, R_{7}=H$

$17 \mathbf{R}_{1}=\mathrm{Me}, \mathbf{R}_{2}=\mathrm{Me}, \mathbf{R}_{3}=\mathrm{t}-\mathrm{Bu}, \mathbf{R}_{4}=\mathbf{H}, \mathbf{R}_{5}=\mathbf{O H}, \mathbf{R}_{6}=\mathbf{H}, \mathbf{R}_{7}=\mathrm{H}$

$18 \mathbf{R}_{1}=\mathrm{Me}, \mathbf{R}_{2}=\mathrm{Me}, \mathbf{R}_{3}=\mathrm{t}-\mathrm{Bu}, \mathbf{R}_{4}=\mathrm{OH}, \mathbf{R}_{5}=\mathrm{H}, \mathbf{R}_{6}=\mathrm{H}, \mathbf{R}_{7}=\mathrm{H}$

$19 \mathbf{R}_{1}=\mathrm{Me}, \mathbf{R}_{2}=\mathrm{Me}, \mathbf{R}_{3}=\mathrm{t}-\mathrm{Bu}, \mathbf{R}_{4}=\mathrm{Cl}, \mathbf{R}_{5}=\mathrm{H}, \mathbf{R}_{6}=\mathrm{H}, \mathbf{R}_{7}=\mathbf{H}$

$20 R_{1}=M e, R_{2}=M e, R_{3}=t-B u, R_{4}=\mathrm{Cl}, R_{5}=H, R_{6}=H, R_{7}=\mathrm{NO}_{2}$

$21 \mathbf{R}_{1}=\mathrm{Me}, \mathbf{R}_{2}=\mathrm{Me}, \mathbf{R}_{3}=\mathrm{t}-\mathrm{Bu}, \mathbf{R}_{4}=\mathrm{H}, \mathbf{R}_{5}=\mathrm{H}, \mathbf{R}_{\mathbf{6}}=\mathrm{Cl}, \mathbf{R}_{7}=\mathrm{OH}$

$22 \mathbf{R}_{1}=\mathrm{Me}, \mathbf{R}_{2}=\mathrm{Me}, \mathbf{R}_{3}=\mathrm{t}-\mathrm{Bu}, \mathbf{R}_{4}=\mathrm{Cl}, \mathbf{R}_{5}=\mathrm{H}, \mathbf{R}_{6}=\mathrm{H}, \mathbf{R}_{7}=\mathrm{OH}$

$23 \mathbf{R}_{1}=\mathrm{Me}, \mathbf{R}_{2}=\mathrm{Me}, \mathbf{R}_{3}=\mathbf{t}-\mathrm{Bu}, \mathbf{R}_{4}=\mathrm{Cl}, \mathbf{R}_{5}=\mathrm{H}, \mathbf{R}_{6}=\mathrm{H}, \mathbf{R}_{7}=\mathrm{NH}_{2}$

$24 \mathbf{R}_{1}=\mathrm{Me}, \mathbf{R}_{2}=\mathrm{Me}, \mathbf{R}_{3}=\mathrm{t}-\mathrm{Bu}, \mathbf{R}_{4}=\mathrm{Cl}, \mathbf{R}_{5}=\mathrm{H}, \mathbf{R}_{6}=\mathrm{H}, \mathbf{R}_{7}=\mathbf{C N}$

$25 \mathbf{R}_{1}=\mathrm{Me}, \mathbf{R}_{2}=\mathrm{Me}, \mathbf{R}_{3}=\mathrm{i}-\mathrm{Pr}, \mathbf{R}_{4}=\mathrm{Cl}, \mathbf{R}_{5}=\mathrm{H}, \mathbf{R}_{\mathbf{6}}=\mathrm{H}, \mathbf{R}_{7}=\mathrm{CN}$

$26 \mathbf{R}_{1}=\mathrm{Me}, \mathbf{R}_{2}=\mathrm{Me}, \mathbf{R}_{3}=\mathrm{i}-\mathrm{Pr}, \mathbf{R}_{4}=\mathrm{F}, \mathbf{R}_{5}=\mathrm{H}, \mathbf{R}_{6}=\mathbf{H}, \mathbf{R}_{7}=\mathrm{CN}$

$27 \mathbf{R}_{1}=\mathrm{Cl}, \mathbf{R}_{2}=\mathrm{Me}, \mathbf{R}_{3}=\mathrm{i}-\mathrm{Pr}, \mathbf{R}_{4}=\mathrm{Cl}, \mathbf{R}_{5}=\mathrm{H}, \mathbf{R}_{6}=\mathbf{H}, \mathbf{R}_{7}=\mathbf{C N}$

$28 R_{1}=M e, R_{2}=M e, R_{3}=$ i-Pr $R_{4}=C N, R_{5}=H, R_{6}=H, R_{7}=C N$

$29 \mathbf{R}_{1}=\mathrm{Cl}, \mathbf{R}_{2}=\mathrm{Me} \mathrm{R} \mathbf{R}_{3}=\mathrm{i}-\mathrm{Pr}, \mathbf{R}_{4}=\mathrm{Cl}, \mathrm{R}_{5}=\mathrm{H}, \mathbf{R}_{6}=\mathrm{H}, \mathrm{R}_{7}=\mathrm{CN}$

$30 R_{1}=C l, R_{2}=M e, R_{3}=\mathrm{i}-\mathrm{Pr}, \mathrm{R}_{4}=\mathrm{CN}, \mathrm{R}_{5}=\mathrm{H}, \mathrm{R}_{6}=\mathrm{H}, \mathrm{R}_{7}=\mathrm{CN}$

$31 \mathbf{R}_{1}=\mathrm{Me}, \mathbf{R}_{2}=\mathrm{Me}, \mathbf{R}_{3}=\mathrm{t}-\mathrm{Bu}, \mathbf{R}_{4}=\mathrm{Cl}, \mathbf{R}_{5}=\mathrm{H}, \mathbf{R}_{6}=\mathrm{H}, \mathbf{R}_{7}=\mathrm{COOMe}$ 


\section{METHODS, MODELS AND CALCULATIONS}

As the method employed here has been discussed in detail elsewhere ${ }^{17-20}$, we shall only present a brief sketch here. Let us consider a state of thermodynamic equilibrium and a 1:1 stoichiometry in the formation of the drug-enzyme complex:

$$
\mathrm{D}_{\mathrm{i}}+\mathrm{RT} \mathrm{D}_{\mathrm{i}} \mathrm{RT}
$$

where $\mathrm{D}_{\mathrm{i}}$ is the drug, RT the reverse transcriptase, and $\mathrm{D}_{\mathrm{i}} \mathrm{RT}$ is the drugenzyme complex.

We consider the following situation. The drug-enzyme interaction is governed by weak interactions, the receptor's conformation is so strongly preferred that the binding energy is accounted for entirely in terms of local atomic interactions, the total molecular partition functions can be factorized in terms of independent and uncoupled translational, rotational, vibrational and electronic partition functions; and only the electronic ground state is important in the electronic partition function. In this case the equilibrium constant, $\mathrm{K}$, for Eq. (1) can be expressed as ${ }^{17-20}$ :

$$
\log \mathrm{K}_{\mathrm{i}}=\mathrm{a}+\mathrm{b} \log \mathrm{M}_{\mathrm{Di}}+\mathrm{c} \log \sigma_{\mathrm{Di}}+\mathrm{d} \log \left(\mathrm{I}_{1} \mathrm{I}_{2} \mathrm{I}_{3}\right)+\mathrm{e} \Delta \mathrm{E}_{\mathrm{i}}
$$

where a, b, c, d and e are constants, D refers to the drug molecule, $\sigma$ is the symmetry number, $M$ the drug's molecular mass, $\mathrm{I}_{1} \mathrm{I}_{2} \mathrm{I}_{3}$ is the product of the three moments of inertia about the three principal axes of rotation ${ }^{17}$, and $\Delta \mathrm{E}$ is the drug-RT interaction energy. The interaction energy, $\Delta \mathrm{E}$, cannot be determined directly, either due to the size of the receptor or to lack knowledge of its molecular structure. Nevertheless, when we consider a drug-receptor interaction in which no covalent bonds are formed (i.e., a weak interaction), we can employ Perturbation Theory to evaluate $\Delta \mathrm{E}$. The final expression is ${ }^{20}$ :

$$
\begin{gathered}
\Delta E=W+\sum_{i}\left[E_{i} Q_{i}+X_{i} S_{i}^{E}+G_{i} S_{i}^{N}\right]+\sum_{i} \sum_{m}\left[H_{i}(m) F_{i}(m)+J_{i}(m) S_{i}^{E}(m)\right]+ \\
\sum_{i} \sum_{\mathbb{m}^{\prime}}\left[R_{i}\left(m^{\prime}\right) F_{i}\left(m^{\prime}\right)+T_{i}\left(m^{\prime}\right) S_{i}^{H}\left(m^{\prime}\right)\right]
\end{gathered}
$$

where $\mathrm{W}, \mathrm{E}, \mathrm{X}, \mathrm{G}, \mathrm{H}, \mathrm{J}, \mathrm{R}$, and $\mathrm{T}$ are constants. $\mathrm{Q}_{\mathrm{i}}$ is the net charge of atom $\mathrm{i} . \mathrm{S}_{\mathrm{i}}^{\mathrm{E}}$ and $\mathrm{S}_{\mathrm{i}}^{\mathrm{N}}$ are, respectively, the total atomic electrophilic (ESD) and nucleophilic superdelocalizabilities (ESN) of atom i defined $\mathrm{as}^{20}$ :

$$
\boldsymbol{S}_{i}^{E}=2 \sum_{m} \sum_{r} \frac{C_{m r}^{2}}{\boldsymbol{E}_{m}}
$$

where the summation on $\mathrm{m}$ is over the occupied MO's and the one on $\mathrm{r}$ is over the AO coefficients of atoms i contributing to one MO, and:

$$
S_{i}^{N}=2 \sum_{m^{\prime}} \sum_{r} \frac{C_{m^{\prime} r}^{2}}{E_{m^{\prime}}}
$$

where the summation on m' is now over the virtual MO's

These reactivity indices can be directly interpreted. Within a given molecule, $\mathrm{S}$ E represents the relative capacity to transfer electrons to an electrondeficient center and $\mathrm{S}_{\mathrm{i}}^{\mathrm{N}}$ represents the relative capacity to accept electrons. $\mathrm{F}(\mathrm{m})$ is the Fukui function of atom i at MO $\mathrm{m}$ (or $\left.\mathrm{m}^{\prime}\right)^{21,22}$. Particular cases of the Fukui index are the well-known $\mathrm{f}_{i}^{-}$and $\mathrm{f}_{i}^{+}$indices that correspond, in our nomenclature, to $\mathrm{F}_{(}(\mathrm{HOMO})$ and $\mathrm{F}_{\mathrm{i}}(\mathrm{LUMO})$ respectively ${ }^{22}$. Note that these definitions of the Fukui function are simply the total gross populations of atom $i$ at the HOMO $\left(f_{i}^{-}\right)$and LUMO $\left(f_{i}^{+}\right)$as defined by Mulliken ${ }^{23}$. Under a different nomenclature, the whole family of Fukui indices has been employed in our group for more than 20 years in structure-activity studies (see for example Refs. 18-20). Regarding the interpretation of the Fukui indices, it is suggested that the more electrophilic site in a molecule is the one corresponding to the highest value of the electrophilic Fukui index for the HOMO (i.e., $f_{i}^{-}=F_{i}(H O M O)$ ). The highest value of $\mathrm{f}_{\mathrm{i}}^{+}$in a molecule indicates the atom most prone to undergo a nucleophilic attack ${ }^{24}$.

We must emphasize that only drug-related terms appear in equations 2 and 3. This is so because in the model employed to derive them it is assumed that we are dealing with a family drugs interacting with the same partner (RT in this case). Then, the electronic terms of the RT are constants that do not appear explicitly.

Regarding the product of the moments of inertia, it has been proposed that it can be expressed in a first approximation as ${ }^{25,26}$ :

$$
\log \left(I_{1} I_{2} I_{3}\right)=\sum_{t} \sum_{i} m_{i, t} R_{i, t}^{2}=\sum_{t} O_{t}
$$

where the summation over $\mathrm{t}$ is over the different substituents of the molecule, $m_{i}$ is the mass of the $\mathrm{i}$-th atom belonging to the $\mathrm{r}$-th substituent, $\mathrm{R}_{\mathrm{i}}$ being its distance to the atom to which the substituent is attached. We must note here that this approximation enables us to transform a molecular property (i.e., $\left.\log \left(\mathrm{I}_{1} \mathrm{I}_{2} \mathrm{I}_{3}\right)\right)$ into a sum of local properties. We have called the right side of equation 6 the substituent's orientational parameter $(\mathrm{OP})^{26}$.

Inserting equations 6 and 3 into equation 2 we obtain the KlopmanPeradejordi-Gómez approach (KPG) ${ }^{20}$ expressing the relationship between the variation of a biological activity with the variation of the reactivity indices of atoms of the drug molecules only. We also assume that the molecules interact with their target through a common skeleton, the substituents only modulating the electronic properties of that skeleton. The KPG approach has produced excellent results for very different biologically active molecules ${ }^{18-20,25-30}$.

In this case, the following molecular systems were selected:

a. A series of TBS derivatives active against WT-RT (molecules 1-30 in Figure 1).

b. A series of TBS derivatives active against K103N-RT (molecules 1, 2, 5, 6, 8, 9, 10-13, 17, 19, 22, 23, 25 and 27-30 in Figure 1).

c. A series of TBS derivatives active against Y181C-RT (molecules 1-10, 12, 13, 16-19 and 22-31 in Figure 1).

The values for the inhibitory activities against WT-RT, K103N-RT, and Y181C-RT were taken from the literature $[15,16]$.

All the calculations were performed with the Hyperchem package ${ }^{31}$. Due to the size of the molecular systems, full geometry optimization was carried out using the AM1 semiempirical methodology ${ }^{32}$. The method selected for calculating the wave function was Zerner's ZINDO/1 ${ }^{33,34}$. This choice is justified because ZINDO/1 is the only method producing positive nucleophilic superdelocalizabilities as required by the mode ${ }^{35}$. The necessary information to calculate the reactivity indices was extracted from Hyperchem output files with software written in our Laboratory.

We must stress that the working equation must have a mathematical solution because it belongs to the family of model-based methods ${ }^{36}$. The problem is that the number of molecules is generally less than the number of unknown quantities. For this reason statistical analysis is employed to find the best solution. The statistical fitting of equation 2 was performed by means of a stepwise regression technique with the inhibitory activities as dependent variables and the static reactivity indices of the atoms belonging to a common skeleton as independent variables. This common skeleton is depicted in Figure 2. We added the OP of substituents located at positions 1, 2, and 4 on the thiazole ring, and substituents at positions $11,12,14$, and 15 on the phenyl ring (see Figure 2). Their numerical values are shown in Table 1. Taking into account that in aromatic systems many independent variables are highly intercorrelated and stable estimates for the regression coefficients cannot be obtained via ordinary least squares methods, we employed Ridge regression analysis $^{37-39}$. The Statistical Software Package was employed ${ }^{40}$.

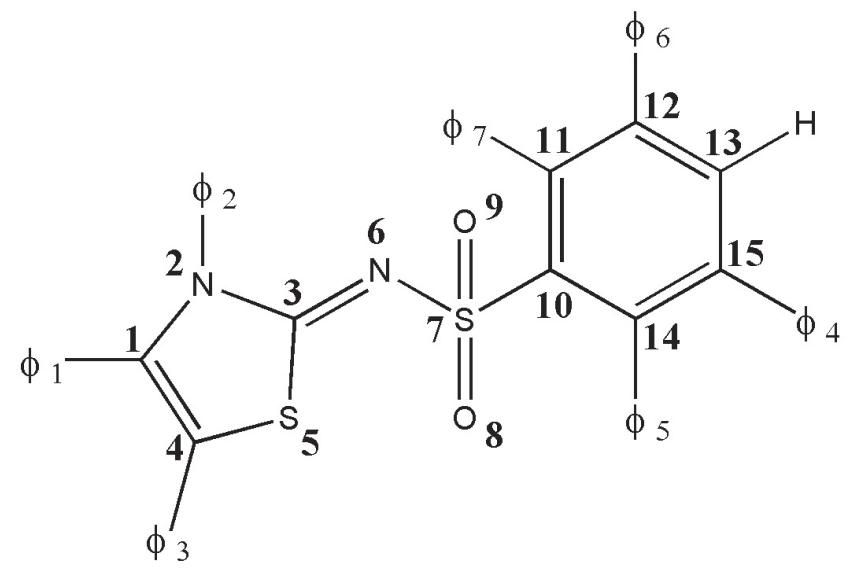


Table 1. Numerical values of the Orientational Parameters.

\begin{tabular}{|c|c|}
\hline Substituent & Orientational parameter $\left(\right.$ uma $\left.\AA^{2}\right)$ \\
\hline$-\mathrm{H}$ & 1.22 \\
\hline$-\mathrm{Me}$ & 40.26 \\
\hline$-\mathrm{t}-\mathrm{Bu}$ & 332.49 \\
\hline$-\mathrm{Et}$ & 140.67 \\
\hline$-\mathrm{i}-\mathrm{Pr}$ & 234.26 \\
\hline$-\mathrm{CF}_{3}$ & 366.42 \\
\hline$-\mathrm{Cl}$ & 102.58 \\
\hline$-\mathrm{CH}=\mathrm{CH}_{2}$ & 124.42 \\
\hline$-\mathrm{CONH} \mathrm{H}_{2}$ & 223.22 \\
\hline$-\mathrm{CN}$ & 117.96 \\
\hline$-\mathrm{OMe}$ & 124.09 \\
\hline$-\mathrm{F}$ & 34.88 \\
\hline$-\mathrm{NH}$ & 35.12 \\
\hline$-\mathrm{OH}$ & 34.00 \\
\hline$-\mathrm{NO}$ & 203.32 \\
\hline$-\mathrm{COOMe}$ & 428.91 \\
\hline
\end{tabular}

\section{RESULTS}

Several statistical equations were obtained and analyzed. The best ones are the following (we use the notation ... HOMO-2, HOMO-1, HOMO, LUMO, $\mathrm{LUMO}+1, \mathrm{LUMO}+2$....):

For the inhibitory activity of TBS derivatives against WT-RT the best equation is:

$\log \mathrm{IC}_{50}=-12.46-97.55 \mathrm{Q}_{5}+4.46 \mathrm{~S}_{4}{ }^{\mathrm{E}}(\mathrm{HOMO})+7.70 \mathrm{~F}_{6}(\mathrm{HOMO}-2)-$ $9.33 \mathrm{~F}_{13}(\mathrm{LUMO})+0.02 \phi_{6}-6.39 \mathrm{Q}_{11}+8.80 \mathrm{~S}_{2}{ }^{\mathrm{E}}(\mathrm{HOMO}-2)+0.02 \phi_{5}+$ $71.20 \mathrm{~S}_{13}{ }^{\mathrm{E}}(\mathrm{HOMO}-1)-4.22 \mathrm{~S}_{8}^{\mathrm{N}}(\mathrm{LUMO}+1)-5.72 \mathrm{Q}_{13}$

with $\mathrm{n}=30, \mathrm{R}^{2}=0.97, \mathrm{SD}=0.24$ and $\mathrm{F}(11,18)=51.17(\mathrm{p}<0.00000000003)$. Here, $\mathrm{Q}_{5}$ is the net charge of atom $5, \mathrm{~S}^{\mathrm{E}}(\mathrm{HOMO}-2)$ is the orbital $\mathrm{ESD}$ of atom 4 in the third occupied MO, $\mathrm{F}_{6}(\mathrm{HOMO}-2)$ is the Fukui index of atom 6 in the same MO, $\mathrm{F}_{13}(\mathrm{LUMO})$ is the Fukui index of atom 13 in the first empty MO, $\phi_{5}$ is the OP of the substituent attached to atom $14, \phi_{6}$ is the OP for the substituent attached to atom $12, \mathrm{Q}_{11}$ is the net charge of atom $11, \mathrm{~S}_{2}^{\mathrm{E}}(\mathrm{HOMO}-2)$ is the orbital ESD of atom 2 in the third occupied MO, $\mathrm{S}_{13}{ }^{\mathrm{E}}(\mathrm{HOMO}-1)$ is the orbital ESD of atom 13 in the second occupied MO, $\mathrm{S}_{8}{ }^{\mathrm{N}}(\mathrm{LUMO}+1)$ is the orbital NSD of atom 8 in the second empty $\mathrm{MO}$, and $\mathrm{Q}_{13}$ is the net charge of atom 13 . Tables 2,3 , and 4 show, respectively, the experimental and predicted values, the squared internal correlation coefficient matrix and the results of Student's-test.

For the inhibitory activity of TBS derivatives against K103N-RT the best equation is:

$\log \mathrm{IC}_{50}=3.44-11.28 \mathrm{~F}_{13}(\mathrm{HOMO}-2)+5.12 \mathrm{~S}_{5}^{\mathrm{E}}(\mathrm{HOMO}-2)+1.95 \mathrm{~S}_{10}{ }^{\mathrm{E}}(\mathrm{HOMO}-$ $2)+7.83 \mathrm{~F}_{10}(\mathrm{HOMO})$

with $\mathrm{n}=17, \mathrm{R}^{2}=0.87, \mathrm{SD}=0.17$ and $\mathrm{F}(4,12)=20.92\left(\mathrm{p}<\right.$. Here, $\mathrm{F}_{13}$ (HOMO-2 $)$ is the Fukui index of atom 13 in the third occupied MO, $\mathrm{S}_{5}{ }_{5}(\mathrm{HOMO}-2)$ is the orbital ESD of atom 5 in HOMO-2, $\mathrm{S}$ E $(\mathrm{HOMO})$ is the orbital ESD of atom 10 in HOMO-2, and $\mathrm{F}_{10}(\mathrm{HOMO})$ is the Fukui index of atom 10 in the occupied frontier MO. Tables 5, 6, and 7 show, respectively, the experimental predicted values, the squared internal correlation coefficient matrix and the results of Student's-test.

For the inhibitory activity of TBS derivatives against Y181C-RT the best equation is:

$\log \mathrm{IC}_{50}=-44.41-9.03 \mathrm{~S}_{7}{ }^{\mathrm{E}}(\mathrm{HOMO}-2)-287.16 \mathrm{~S}_{13}{ }^{\mathrm{E}}(\mathrm{HOMO})-13.75 \mathrm{~S}_{7}{ }^{\mathrm{E}}(\mathrm{HOMO}-$ $1)+161.46 \mathrm{Q}_{3}-0.01 \phi_{3}-2.11 \mathrm{~S}^{\mathrm{N}}+6.85 \mathrm{~S}_{5}^{\mathrm{E}}(\mathrm{HOMO})+0.92 \mathrm{~S}_{8}{ }^{\mathrm{E}}(\mathrm{HOMO}-2)-$

$0.32 \mathrm{~S}_{15}{ }^{\mathrm{N}}+0.002 \phi_{6}-7.79 \mathrm{~F}_{8}(\mathrm{HOMO}-1)$

with $\mathrm{n}=26, \mathrm{R}^{2}=0.96, \mathrm{SD}=0.23$ and $\mathrm{F}(11,14)=34.99(\mathrm{p}<0.00000003)$. Here, $\mathrm{S}_{7}{ }^{\mathrm{E}}(\mathrm{HOMO})$ is the orbital ESD of the third occupied $\mathrm{MO}$ at atom $7, \mathrm{~S}_{13}{ }^{\mathrm{E}}(\mathrm{HOMO})$ is the orbital ESD of atom 13 in the occupied frontier MO, $\mathrm{S}_{7}{ }_{7}(\mathrm{HOMO}-1)$ is the orbital ESD of atom 7 in the second occupied MO, $Q_{3}$ is the net charge of atom $3, \phi_{3}$ is the OP of the substituent attached to atom $4, \phi$ is the OP for the substituent attached to atom $12, \mathrm{~S}_{11}{ }^{\mathrm{N}}$ is the total atomic NSD of atom 11, $\left.\mathrm{S}_{5}{ }_{5} \mathrm{HOMO}\right)$ is the orbital ESD of atom 5 in the HOMO, $\mathrm{S}_{8}{ }^{\mathrm{E}}(\mathrm{HOMO}-2)$ is the orbital ESD of atom 8 in HOMO-2, $\mathrm{S}_{15}{ }^{\mathrm{N}}$ is the total atomic NSD of atom 15, and $\mathrm{F}_{8}(\mathrm{HOMO}-1)$ is the Fukui index of atom 8 in HOMO-1. Tables 8, 9 and 10 show, respectively, the experimental and predicted $\log \mathrm{IC}_{50}$ values, the squared internal correlation coefficient matrix and the results of Student's-test.

\section{DISCUSSION}

The values of the squared correlation coefficient, the standard deviation and the $\mathrm{F}$ test (with its associated $\mathrm{p}$ value) indicate that Eqs. 7-9 are statistically significant. The results of Student's t-test for each equation show that almost all the variables appearing in the equations are also statistically significant. Therefore, our results indicate that the variation of the TBS-mediated inhibition of HIV-1 RT is related to the variation of a definite set of molecular reactivity indices.

For the sake of the discussion, let us note that the Fukui indices, the NSDs (atomic and total) and the orientational factors are always positive. The ESDs are always negative. The net charges can be positive, negative or zero.

Equation 7 explains the $97 \%$ of the variation of the inhibitory capacities. Examining it and considering in a first approach that all the reactivity indices are totally uncorrelated (this is not always true in aromatic systems), we may see that an ideal molecular system should have the following characteristics (see also Tables 3 and 4) for a good inhibition of WT-RT:

1. Positive net charges on atoms 5 and 11 ,

2. High electron-donor capacities of atoms 2 (in the third occupied MO), 4 (in the HOMO) and 13 (in the second occupied MO),

3. A high electron-acceptor capacity of atom 8 in the second empty MO,

4. Low values of the orientational parameters of the substituents attached to atoms 12 and 14 , and

5. A low value for the Fukui index for atom 6 in the third occupied MO and a high one for atom 13 in the LUMO.

It is clear that this interaction is steric- (the OPs), charge-, and orbitalcontrolled.

Table 2. Experimental and calculated constants for the inhibition of WTRT by TBS derivatives.

\begin{tabular}{|c|c|c|}
\hline Molecule $^{\mathrm{a}}$ & $\begin{array}{l}\text { Experimental } \\
\log \mathrm{IC}_{50}^{\mathrm{b}}(\mu \mathrm{M})\end{array}$ & $\begin{array}{c}\text { Calculated } \\
\log \mathrm{IC}_{50}{ }^{\mathrm{c}}(\mu \mathrm{M})\end{array}$ \\
\hline 1 & -0.43 & -0.58 \\
\hline 2 & -0.57 & -0.59 \\
\hline 3 & 0.78 & 0.80 \\
\hline 4 & -0.01 & -0.24 \\
\hline 5 & -0.07 & -0.14 \\
\hline 6 & -0.47 & -0.53 \\
\hline 7 & -0.22 & -0.39 \\
\hline 8 & -0.22 & -0.07 \\
\hline 9 & -1.11 & -1.31 \\
\hline 10 & -0.82 & -0.39 \\
\hline 11 & 1.59 & 1.42 \\
\hline 12 & -0.21 & -0.17 \\
\hline 13 & -0.52 & -0.37 \\
\hline 14 & 1.70 & 1.72 \\
\hline 15 & 0.94 & 0.98 \\
\hline 16 & 0.69 & 0.70 \\
\hline 17 & 0.20 & 0.11 \\
\hline 18 & 0.94 & 0.91 \\
\hline 19 & -0.52 & -0.44 \\
\hline 20 & 0.38 & 0.42 \\
\hline 21 & 0.80 & 0.80 \\
\hline 22 & -1.49 & -1.64 \\
\hline 23 & -0.72 & -0.56 \\
\hline 24 & -0.74 & -0.80 \\
\hline 25 & -1.96 & -1.77 \\
\hline 26 & -1.04 & -1.43 \\
\hline 27 & -2.03 & -2.11 \\
\hline 28 & -1.92 & -1.49 \\
\hline 29 & -2.05 & -1.98 \\
\hline 30 & -2.02 & -1.99 \\
\hline
\end{tabular}

$\begin{array}{lll}\text { a. Figure } 1 & \text { b. From Refs. } 15 \text { and } 16 & \text { c. Using Eq. } 7\end{array}$ 
Table 3. Squared correlation coefficient matrix for the variables appearing in equation 7 .

\begin{tabular}{|c|c|c|c|c|c|c|c|c|c|c|}
\hline & $\mathrm{S}_{4}^{\mathrm{E}}(\mathrm{HOMO})$ & $\mathrm{F}_{6}(\mathrm{HOMO}-2)$ & $\mathrm{F}_{13}(\mathrm{LUMO})$ & $\phi_{6}$ & $\mathrm{Q}_{11}$ & $\mathrm{~S}_{2}{ }^{\mathrm{E}}(\mathrm{HOMO}-2)$ & $\phi_{5}$ & $\mathrm{~S}_{13}{ }^{\mathrm{E}}(\mathrm{HOMO}-1)$ & $\mathrm{S}_{8}{ }^{\mathrm{N}}(\mathrm{LUMO}+1)$ & $\mathrm{Q}_{13}$ \\
\hline $\mathrm{Q}_{5}$ & 0.60 & 0.10 & -0.11 & -0.17 & 0.52 & 0.19 & -0.30 & -0.07 & -0.38 & -0.09 \\
\hline $\mathrm{S}_{4}{ }^{\mathrm{E}}(\mathrm{HOMO})$ & 1.00 & 0.02 & 0.06 & -0.15 & 0.22 & -0.12 & -0.22 & -0.32 & -0.25 & 0.25 \\
\hline $\mathrm{F}_{13}(\mathrm{LUMO})$ & & & 1.00 & 0.37 & -0.33 & 0.05 & -0.22 & -0.03 & 0.34 & 0.02 \\
\hline$\phi_{6}$ & & & & 1.00 & -0.02 & -0.30 & -0.04 & 0.13 & 0.25 & -0.04 \\
\hline $\mathrm{S}_{2}{ }^{\mathrm{E}}(\mathrm{HOMO}-2)$ & & & & & & 1.00 & -0.16 & -0.10 & -0.36 & -0.01 \\
\hline$\phi_{5}$ & & & & & & & 1.00 & -0.003 & 0.33 & 0.31 \\
\hline $\mathrm{S}_{13}{ }^{\mathrm{E}}(\mathrm{HOMO}-1)$ & & & & & & & & 1.00 & 0.11 & -0.22 \\
\hline $\mathrm{S}_{8}{ }^{\mathrm{N}}(\mathrm{LUMO}+1)$ & & & & & & & & & 1.00 & -0.10 \\
\hline
\end{tabular}

Table 4. Results of Student's-test for the significance of variables appearing in equation 7.

\begin{tabular}{|c|c|c|}
\hline Variable & $\mathrm{t}$ & $\mathrm{p}$ \\
\hline $\mathrm{Q}_{5}$ & -13.02 & $<0.0000000001$ \\
\hline $\mathrm{S}_{4}{ }^{\mathrm{E}}(\mathrm{HOMO})$ & 10.54 & $<0.000000004$ \\
\hline $\mathrm{F}_{6}(\mathrm{HOMO}-2)$ & 7.77 & $<0.0000004$ \\
\hline $\mathrm{F}_{13}(\mathrm{LUMO})$ & -5.96 & $<0.00001$ \\
\hline$\phi_{6}$ & 5.94 & $<0.00001$ \\
\hline $\mathrm{Q}_{11}$ & -5.09 & $<0.00008$ \\
\hline $\mathrm{S}_{2}{ }^{\mathrm{E}}(\mathrm{HOMO}-2)$ & 5.75 & $<0.00002$ \\
\hline$\phi_{5}$ & 6.49 & $<0.000004$ \\
\hline $\mathrm{S}_{13}{ }^{\mathrm{E}}(\mathrm{HOMO}-1)$ & 4.54 & $<0.0003$ \\
\hline $\mathrm{S}_{8}{ }^{\mathrm{N}}(\mathrm{LUMO}+1)$ & -4.65 & $<0.0002$ \\
\hline $\mathrm{Q}_{13}$ & -3.16 & $<0.005$ \\
\hline
\end{tabular}

First we note that the appearance of reactivity indices associated with MOs other than the frontier ones and the absence of the latter can be explained in the following two ways: either the frontier MOs absent from the equation do not contribute at a certain atom, or the variation of their value throughout the molecules studied is not statistically significant (because its value is nearly constant).

Figure 3 displays a summary of the proposed interaction mechanism.

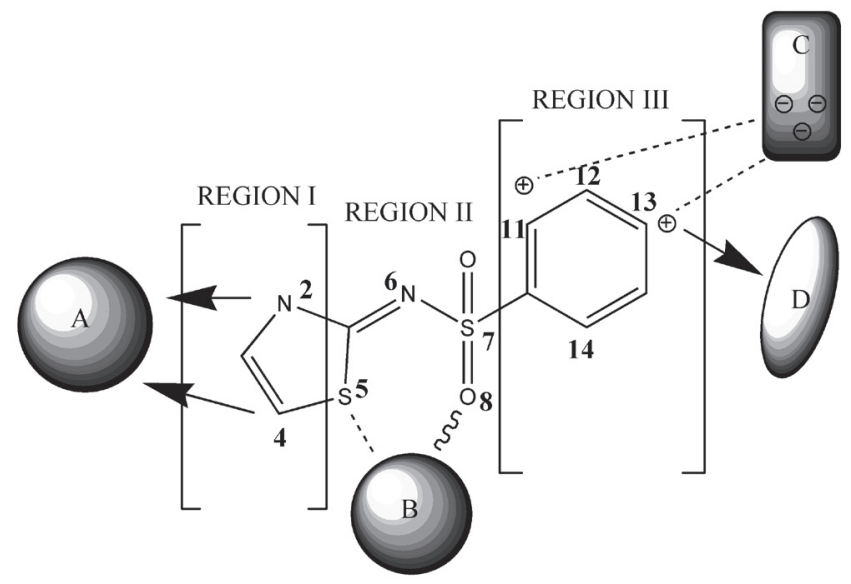

Table 5. Experimental and calculated constants for the inhibition of K103N-RT by TBS derivatives.

\begin{tabular}{|c|c|c|}
\hline Molecule $^{\mathrm{a}}$ & $\begin{array}{c}\text { Experimental } \\
\log \mathrm{IC}_{50}{ }^{\mathrm{b}}(\mu \mathrm{M})\end{array}$ & $\begin{array}{c}\text { Calculated } \\
\log \mathrm{IC}_{50}{ }^{c}(\mu \mathrm{M})\end{array}$ \\
\hline 1 & 1.51 & 1.43 \\
\hline 2 & 1.11 & 1.11 \\
\hline 5 & 0.80 & 0.87 \\
\hline 6 & 1.30 & 0.89 \\
\hline 8 & 1.62 & 1.53 \\
\hline 9 & 0.84 & 0.70 \\
\hline 10 & 0.79 & 0.75 \\
\hline 13 & 1.04 & 1.17 \\
\hline 17 & 1.48 & 1.42 \\
\hline 19 & 1.04 & 1.06 \\
\hline 22 & 0.04 & -0.06 \\
\hline 23 & 1.23 & 1.32 \\
\hline 25 & 0.77 & 0.88 \\
\hline 27 & 0.59 & 0.62 \\
\hline 28 & 0.61 & 0.70 \\
\hline 29 & 0.57 & 0.78 \\
\hline 30 & 0.48 & 0.65 \\
\hline
\end{tabular}

$\begin{array}{lll}\text { a. Figure } 1 & \text { b. From Refs. } 15 \text { and } 16 & \text { c. Using Eq. } 8\end{array}$

In Region I, some atoms of the thiazole ring are donating electrons towards an electron-deficient center of RT (denoted as A). This can be explained by suggesting that the thiazole ring is engaged in a slip stacked $\pi-\pi$ interaction ${ }^{41}$.

In Region II, it seems that atom 5 interacts electrostatically with a negatively charged site in RT (denoted as B), or with site A. The participation of the second empty $\mathrm{MO}$ of atom 8 will be interpreted here as providing a site for the approach of a high electron density from RT for a $\pi-\pi$ interaction with site $\mathrm{B}$. This interpretation is coherent with the requirement of a positive charge on atom 5 (if atom 5 interacts with site B) and with a low value of the Fukui index of atom 6 (in the third occupied MO).

Region III seems to exhibit a more complex interaction pattern. The low values for the orientational parameters suggest that the phenyl ring should have a certain conformational flexibility to fit the interaction site. Also, it seems that there is an electrostatic interaction between parts of Region III and a negative site in RT (denoted as C). Atom 13 seems to be engaged in interactions with two atoms or groups of atoms: one is electrostatic (through its positive net charge and the high value of its Fukui index at the LUMO), and the other is a charge transfer from the second occupied MO towards an electron-deficient area in the RT (denoted as D). If this is correct, both interacting sites in RT must be located at opposite faces of the phenyl ring. Site $\mathrm{C}$ could correspond to 
a carboxylate moiety or to $\mathrm{OH}$ lone pair electrons. The interaction with site $\mathrm{D}$ could correspond to another $\pi-\pi$ interaction (edge-to-face or slip stacked).

Table 6. Squared correlation coefficient matrix for the variables appearing in equation 8 .

\begin{tabular}{|c|c|c|c|}
\hline & $\mathrm{S}_{5}{ }^{\mathrm{E}}($ HOMO-2) & $\mathrm{S}_{10}{ }^{\mathrm{E}}($ HOMO-2 $)$ & $\mathrm{F}_{10}(\mathrm{HOMO})$ \\
\hline $\mathrm{F}_{13}($ HOMO-2) & 0.56 & 0.05 & -0.65 \\
\hline $\mathrm{S}_{5}{ }^{\mathrm{E}}($ HOMO-2) & 1.00 & -0.48 & -0.30 \\
\hline $\mathrm{S}_{10}{ }^{\mathrm{E}}($ HOMO-2) & & 1.00 & -0.49 \\
\hline
\end{tabular}

Table 7. Results of Student's-test for the significance of the variables appearing in equation 8 .

\begin{tabular}{|c|c|c|}
\hline Variable & $\mathrm{t}$ & $\mathrm{p}$ \\
\hline $\mathrm{F}_{13}($ HOMO-2 $)$ & -5.45 & $<0.0002$ \\
\hline $\mathrm{S}_{5}{ }^{\mathrm{E}}(\mathrm{HOMO}-2)$ & 8.08 & $<0.000003$ \\
\hline $\mathrm{S}_{10}{ }^{\mathrm{E}}(\mathrm{HOMO}-2)$ & 6.64 & $<0.00002$ \\
\hline $\mathrm{F}_{10}($ HOMO $)$ & 3.22 & $<0.007$ \\
\hline
\end{tabular}

Table 8. Experimental and calculated constants for the inhibition of Y181C-RT by TBS derivatives.

\begin{tabular}{|c|c|c|}
\hline Molecule $^{\mathrm{a}}$ & $\begin{array}{l}\text { Experimental } \\
\log \mathrm{IC}_{50}^{\mathrm{b}}(\mu \mathrm{M})\end{array}$ & $\begin{array}{c}\text { Calculated } \\
\log \mathrm{IC}_{50}{ }^{\mathrm{c}}(\mu \mathrm{M})\end{array}$ \\
\hline 1 & -0.33 & -0.40 \\
\hline 2 & -1.18 & -1.42 \\
\hline 3 & -0.92 & -0.86 \\
\hline 4 & 1.52 & 1.47 \\
\hline 5 & -0.33 & -0.09 \\
\hline 6 & -1.15 & -1.15 \\
\hline 7 & -0.15 & -0.05 \\
\hline 8 & -0.59 & -0.75 \\
\hline 9 & -0.89 & -0.69 \\
\hline 10 & 0.98 & 0.74 \\
\hline 12 & -0.19 & -0.38 \\
\hline 13 & -1.36 & -1.38 \\
\hline 16 & 0.71 & 0.90 \\
\hline 17 & -0.39 & -0.32 \\
\hline 18 & 1.15 & 1.09 \\
\hline 19 & -1.36 & -1.46 \\
\hline 22 & -1.96 & -2.06 \\
\hline 23 & -0.96 & -0.98 \\
\hline 24 & -1.16 & -0.89 \\
\hline 25 & -0.70 & -0.72 \\
\hline 26 & 0.32 & 0.21 \\
\hline 27 & -1.68 & -1.49 \\
\hline 28 & -0.33 & -0.54 \\
\hline 29 & -1.04 & -0.92 \\
\hline 30 & -0.68 & -0.42 \\
\hline 31 & 1.00 & 0.91 \\
\hline
\end{tabular}

a. Figure 1

b. From Refs. 15 and 16

c. Using Eq. 9

If we apply the same analysis to Eq. 8 (which explains $87 \%$ of the variation of the inhibitory capacity) we observe that a high inhibitory capacity of the molecules against K103N-RT is associated with:

1. High electron-donating capacities of atoms 5 and 10 in the third occupied MO,

2. A high value of the Fukui index of atom 13 in the second occupied MO, and

3. A low value of the Fukui index of atom 10 in the HOMO

Atom 10 seems to interact by donating electrons to a center in RT. This interaction seems to occur through the inner occupied MOs because of the low value of the Fukui index associated with the HOMO. Again, atom 13 appears to be donating charge to a RT center. The appearance of the ESD of atom 5 in the third occupied $\mathrm{MO}$ suggests a charge transfer from this atom to an electrondeficient center. All these results can be integrated by suggesting that the thiazole and phenyl rings are engaged separately in $\pi-\pi$ stacking interactions with aromatic moieties of RT.

The whole inhibitory process seems to be only orbital-controlled.

In the case of Eq. 9, which explains $96 \%$ of the variation of the inhibitory capacity, an optimal activity against Y181C-RT is associated with:

1. A low value of the orientational parameter of the substituents attached to atom 12 and a high one in the case of substituents attached to atom 4 ,

2. A negative net charge on atom 3 ,

3. A low electron-donating capacity of atoms 7 (at the level of the first and second occupied MOs) and 13 (at the level of the HOMO),

4. A high electron-donating capacity of atoms 5 (at the HOMO level) and 8 (at the first and second occupied MOs), and

5. A high electron-acceptor capacity of atoms 11 and 15.

It seems that, for this specific group pf molecules, their interaction with RT seems to be only charge-controlled.

We have divided the molecular skeleton into three regions, as in the case of WT-RT inhibitors (Fig. 4).

A statistically significant high value for the orientational parameter associated with the substituents attached to atom 3 suggests that the thiazole ring should lack conformational freedom, unlike the phenyl ring. This situation could indicate that the five-membered ring should interact first with the Y181C$\mathrm{RT}$, the phenyl ring later adopting an optimal position for interaction. We note that, when substituents are of the alkyl type, the standard interpretation is to suggest that they interact with a hydrophobic site ${ }^{15}$. We hold that this has never been the correct interpretation. We suggest that as the size of the substituents increases, this allows the molecule to move more slowly, giving it more time in the proximity of the electrostatic potential of RT and thus allowing it to be captured and to engage in the interaction.

In Region I atom 3 interacts electrostatically with a positive atom or group of RT (depicted A in Fig. 4). Atom 5 donates electrons to a site labeled B. As atom 8 also donates electrons we have supposed that this could occur in the same site B. The Sulphur atom (atom 7) should have a low electrondonating capacity. This is congruent with the hypothesis of an electron-rich RT area (denoted as C in Fig. 4) located between atoms 7 and 11. This area can thus transfer electrons towards atom 11 . Atom 15 should have a high electronaccepting capacity while atom 13 should have a low electron-donating capacity. Both conditions can be integrated by suggesting that the phenyl ring interacts with an aromatic site of RT (denoted as D in Fig. 4). A variant of this hypothesis is to consider that atom 11 also receives electrons from site D. In this last case the phenyl ring is engaged in a $\pi-\pi$ stacking interaction.

In this case the interaction process is sterically-, charge- and orbitalcontrolled.

In summary, we have observed, starting from a model-based method, the following facts:

1. The variation of the inhibitory capacity of TBS against the three types of HIV-1 RTs is regulated by different mechanisms.

2. As expected in a highly specific interaction, molecular orbitals other than the frontier ones seem to regulate the inhibition of RT by TBS.

3. The increase of the inhibitory capacity with increasing size of some substituents is not attributable to their interaction with a hydrophobic site but to their effect on the distribution of the rotational velocities.

4. Specific $\pi-\pi$ stacking interactions are the main components of the TBS-RT coupling.

5. For each type of RT, the results provide a list of sites in the common skeleton that can be modulated through substitution to improve the inhibitory capacity. 
Table 9. Squared correlation coefficient matrix for the variables appearing in equation 9.

\begin{tabular}{|c|c|c|c|c|c|c|c|c|c|c|}
\hline & $\mathrm{Q}_{3}$ & $\mathrm{~S}_{5}{ }^{\mathrm{E}}(\mathrm{HOMO})$ & $\mathrm{S}_{13}{ }^{\mathrm{E}}(\mathrm{HOMO})$ & $\phi_{3}$ & $\mathrm{~S}_{15}{ }^{\mathrm{N}}$ & $\phi_{6}$ & $\begin{array}{c}\mathrm{S}_{7} \mathrm{E}^{\mathrm{E}}(\mathrm{HOMO}- \\
1)\end{array}$ & $\mathrm{S}_{11}^{\mathrm{N}}$ & $\begin{array}{c}\mathrm{S}_{8}{ }^{\mathrm{E}}(\mathrm{HOMO}- \\
2)\end{array}$ & $\mathrm{F}_{8}(\mathrm{HOMO}-1)$ \\
\hline $\mathrm{S}_{7}{ }^{\mathrm{E}}(\mathrm{HOMO}-2)$ & 0.19 & -0.10 & 0.02 & 0.10 & -0.13 & 0.01 & -0.03 & 0.05 & 0.72 & 0.01 \\
\hline $\mathrm{Q}_{3}$ & 1.00 & -0.56 & 0.60 & 0.35 & -0.02 & -0.04 & 0.03 & -0.04 & -0.00 & -0.29 \\
\hline $\mathrm{S}_{13}{ }^{\mathrm{E}}(\mathrm{HOMO})$ & & & 1.00 & 0.25 & 0.11 & -0.32 & -0.06 & -0.02 & -0.16 & -0.29 \\
\hline$\phi_{3}$ & & & & 1.00 & -0.44 & 0.13 & 0.05 & -0.57 & -0.19 & -0.49 \\
\hline $\mathrm{S}_{15}{ }^{2} \mathrm{~N}$ & & & & & 1.00 & -0.02 & 0.23 & 0.66 & 0.17 & 0.15 \\
\hline $\mathrm{S}_{7}{ }^{\mathrm{E}}(\mathrm{HOMO}-1)$ & & & & & & & 1.00 & 0.36 & 0.28 & -0.56 \\
\hline $\mathrm{S}_{11}^{\mathrm{N}}$ & & & & & & & & 1.00 & 0.44 & 0.29 \\
\hline $\mathrm{S}_{8}{ }^{\mathrm{E}}(\mathrm{HOMO}-2)$ & & & & & & & & & 1.00 & -0.003 \\
\hline
\end{tabular}

Table 10. Results of Student's-test for the significance of the variables appearing in equation 9 .

\begin{tabular}{|c|c|c|}
\hline Variable & $\mathrm{t}$ & $\mathrm{p}$ \\
\hline $\mathrm{S}_{7}{ }^{\mathrm{E}}(\mathrm{HOMO}-2)$ & -9.88 & $<0.0000001$ \\
\hline $\mathrm{S}_{13}{ }^{\mathrm{E}}(\mathrm{HOMO})$ & -3.69 & $<0.002$ \\
\hline $\mathrm{S}_{7}{ }^{\mathrm{E}}(\mathrm{HOMO}-1)$ & -4.84 & $<0.0003$ \\
\hline $\mathrm{Q}_{3}$ & 9.02 & $<0.0000003$ \\
\hline$\phi_{3}$ & -10.47 & $<0.00000005$ \\
\hline $\mathrm{S}_{11}{ }^{\mathrm{N}}$ & -7.39 & $<0.000003$ \\
\hline $\mathrm{S}_{5}{ }^{ }(\mathrm{HOMO})$ & 6.40 & $<0.00002$ \\
\hline $\mathrm{S}_{8}{ }^{\mathrm{E}}(\mathrm{HOMO}-2)$ & 5.59 & $<0.00007$ \\
\hline $\mathrm{S}_{15}{ }^{\mathrm{N}}$ & -4.38 & $<0.0006$ \\
\hline$\phi_{6}$ & 3.17 & $<0.007$ \\
\hline $\mathrm{F}_{8}(\mathrm{HOMO}-1)$ & -3.11 & $<0.008$ \\
\hline
\end{tabular}

\section{REFERENCES}

1. F. J. Pallela Jr, K. M. Delaney, A. C. Moorman, M. O. Loveless, J. Fuhrer, and G. A. Satten. N. Engl. J. Med. 338, 853 (1998).

2. D. D. Richman. Nature 410, 995 (2001).

3. M. Louie and M. Markowitz. Antiviral Res. 55, 15 (2002).

4. J. M. Kilby, S. Hopkins, T. M. Venetta, B. DiMassimo, G. A. Cloud, J. Y. Lee, L. Alldredge, E. Hunter, D. Lambert, D. Bolognesi, T. Matthews, M. R. Johnson, M. A. Nowak, G. M. Shaw, and M. S. Saag. Nature Med. 4, 1302 (1998).

5. R. Garg, S. P. Gupta, H. Gao, M. S. Babu, A. K. Debnath, and C. Hansch. Chem. Rev. 99, 3525 (1999).

6. F. Di Marzo Veronese, T. D. Copeland, A. L. DeVico, R. Rahman, S. Oroszlan, R. C. Gallo, and M. G. Sarngadharan. Science 231, 1289 (1986).

7. S. P. Goff. J. Acquired Immune Defic. Syndr. 3, 817 (1990).

8. V. J. Merluzzi, K. D. Hargrave, M. Labadia, K. Grozinger, M. Skoog, J. C. Wu, C. K. Shih, K. Eckner, D. Hattox, J. Adams, A. S. Rosenthal, R. Faanes, R. J. Eckner, R. A. Karp, and J. L. Sullivan. Science 250, 1411 (1990).

9. W. W. Freimut. Adv. Exp. Med. Biol. 394, 279 (1996).

10. D. Richman, C. K. Shih, I. Lowy, J. Rose, P. Prodanovich, S. Goff, and J. Griffin. Proc. Natl. Acad. Sci. U.S.A. 88, 11241 (1991).

11. D. D. Richman, D. Havlir, J. Corbeil, D. Looney, C. Ignacio, S. A. Spector, J. Sullivan, S. Cheeseman, K. Barringer, D. Pauletti. J. Virol. 68, 1660 (1994).

12. S. J. Smerdon, J. Jager, J. Wang, L. A. Kohlstaedt, A. J. Chirino, J. M. Friedman, P. A. Rice, and T. A. Steitz. Proc. Natl. Acad. Sci. U.S.A. 91, 3911 (1994).

13. C. Tantillo, J. Ding, A. Jacobo-Molina, R. G. Nanni, P. L. Boyer, S. H. Hughes, R. Pauwels, K. Andries, P. A. Janssen, and E. Arnold. J. Mol. Biol. 243, 369 (1994).

14. J. A. Travel, K. D. Miller, and H. Masur. Clin. Infect. Dis. 28, 643 (1999).

15. N. Masuda, O. Yamamoto, M. Fujii, T. Ohgami, J. Fujiyasu, T. Kontani, A. Moritomo, M. Orita, H. Kurihara, H. Koga, H. Nakahara, S. Kageyama, M. Ohta, H. Inoue, T. Hatta, H. Suzuki, K. Sudo, Y. Shimizu, E. Kodama, M. Matsuoka, M. Fujiwara, S. Shigeta, and M. Baba. Bioorg. Med. Chem. 12, 6171 (2004).

16. N. Masuda, O. Yamamoto, M. Fujii, T. Ohgami, J. Fujiyasu, T. Kontani, A. Moritomo, M. Orita, H. Kurihara, H. Koga, S. Kageyama, M. Ohta, H. Inoue, T. Hatta, M. Shintani, H. Suzuki, K. Sudo, Y. Shimizu, E. Kodama, M. Matsuoka, M. Fujiwara, T. Yokota, S. Shigeta, and M. Baba. Bioorg. Med. Chem. 13, 949 (2005).

17. J. S. Gómez-Jeria. Int. J. Quant. Chem. 23, 1969 (1983).

18. J. S. Gómez-Jeria and M. Ojeda-Vergara. Int. J. Quant. Chem. 61, 997 (1997).

19. J. S. Gómez-Jeria and L. Lagos-Arancibia. Int. J. Quant. Chem. 71, 505 (1999).

20. J. S. Gómez-Jeria in J. Maruani Editor, Molecules in Physics, Chemistry and Biology, Vol. 4. Kluwer, Dordrecht, 1989. Pp. 231-251.

21. J. Melin, F. Aparicio, V. Subramanian, M. Galván, and P. K. Chattaraj. J. Phys. Chem. A108, 2487 (2004).

22. A. Aizman and R. Contreras. J. Chil. Chem. Soc. 49, 107 (2004).

23. R. S. Mulliken. J. Chem. Phys. 23, 1833 (1955).

24. P. Pérez, J. Parra-Mouchet, and R. Contreras. J. Chil. Chem. Soc. 49, 51 (2004).

25. J. S. Gómez-Jeria, C. Donoso-Espinoza, and M. Ojeda-Vergara. Mol. Engn. 5, 391 (1995).

26. J. S. Gómez-Jeria and M. Ojeda-Vergara. J. Chil. Chem. Soc. 48, 119 (2003).

27. J. S. Gómez-Jeria, D. Morales-Lagos, B. K. Cassels, and J. C. SaavedraAguilar. Quant. Struct. Act. Relat. 5, 153 (1986).

28. J. S. Gómez-Jeria, B. K. Cassels, and J. C. Saavedra-Aguilar. Eur. J. Med. Chem. 22, 433 (1987).

29. J. S. Gómez-Jeria, L. A. Gerli-Candia, and S. M. Hurtado. J. Chil. Chem. Soc. 49, 307 (2004).

30. J. S. Gómez-Jeria, F. Soto-Morales, and G. Larenas-Gutierrez. Iranian Int. J. Sci. 4, 151 (2003).

31. Hyperchem, V. 5.01. Hypercube Inc. 419 Phillip St., Waterloo, Ontario, Canada.

32. M. J. S. Dewar, E. G. Zoebisch, E. F. Healy, and J. J. P. Stewart. J. Am. Chem. Soc. 107, 3902 (1985).

33. W. D. Edwards, and M. C. Zerner. Theoret. Chim. Acta 72, 347 (1987).

34. W. P. Anderson, W. D. Edwards and M. C. Zerner. Inorg. Chem. 28, 2728 (1986).

35. J. S. Gómez-Jeria. J. Pharm. Sci. 71, 1423 (1982).

36. Y. C. Martin. Quantitative Drug Design, Dekker: New York, 1978.

37. A. E. Hoerl. Chem. Eng. Progr. 58, 54 (1962).

38. P. Schmidt and E. N. Muller. Quality and Quantity 12, 267 (1978).

39. W. W. Rozeboom. Psychol. Bull. 86, 242 (1979).

40. Statistica for Windows. StatSoft, Inc., Tulsa, OK, USA, 1998.

41. E. V. Anslyb and D. A. Dougherty, Modern Physical Organic Chemistry. University Science Books, Sausalito CA, USA, 2006. Pp. 184. 